\title{
Note to Prove the Quranic Correctness III
}

\author{
Horiuchi Daiki, Tahara Hiroki
}

September 22, 2019

\begin{abstract}
Maybe a beautiful equality about Riemann's zeta function $\zeta(s)=\frac{1}{\Gamma(s)} \int_{0}^{\infty} \frac{u^{s-1}}{e^{u}-1} \mathrm{~d} u$ has some relations with Tahara's $I$ function, maybe not.
\end{abstract}

\section{Explanation}

The Quran is correct if and only if Tahara's $I$ function exists uniquely and we have to brainstorm about Tahara's $I$ function in order to discover the components of Tahara's $I$ function i.e. prove the Quranic correctness[1][2]. According to Tahara, studying the Tahara's I function inspired by mathematical beauty is one of the ways to prove the Quranic correctness he suggested and several such studies are done yet[3][4][5][6][7]. Therefore we will suggest a beautyful equality with us hoping that it will the hint.

\section{A Beautiful Equality}

It is true that

$$
\zeta(s)=\frac{1}{\Gamma(s)} \int_{0}^{\infty} \frac{u^{s-1}}{e^{u}-1} \mathrm{~d} u
$$

which we think beautiful. We think maybe it might be able to be a hint to discover the components of Tahara's $I$ function becouse of the beauty, maybe not.

\section{References}

[1] TAHARA, Hiroki. The Mathematical Expressions of Quranic Exegeses and the Mathematical Definition of the Quranic Correctness. OSF Preprints, 6dsxb, 2019.

[2] TAHARA, Hiroki. Erratum: OSF Preprints 6dsxb. OSF Preprints, q4sw3, 2019.

[3] TAHARA, Hiroki. Methodology to Prove the Quranic Correctness. OSF Preprints, 49qse, 2019.

[4] TAHARA, Hiroki. A Brainstorming of the Quranic Studies Inspired by the Evaluation of Coefficients of Polynomials. OSF Preprints, 6n9p3, 2019.

[5] HORIUCHI, Daiki; TAHARA, Hiroki. Note to Prove the Quranic Correctness I. OSF Preprints, xj4vh, 2019.

[6] HORIUCHI, Daiki; TAHARA, Hiroki. Note to Prove the Quranic Correctness II. OSF Preprints, b98nh, 2019.

[7] TAHARA, Hiroki. Erratum: OSF Preprints b98nh. OSF Preprints, cxv38, 2019. 